\title{
Pre-employment lung function at age 16 years as a guide to lung function in adult life
}

\author{
D J Chinn, J E Cotes, M Fechner, C Elliott
}

\begin{abstract}
Background-A study was conducted to find out if pre-employment lung function at age 16 improved the estimation of that between ages 25 to 27 compared with the use of reference values based on smoking history, stature, body mass index, and other concurrent anthropometric variables.

Methods-Apprentices attending a shipyard training school were assessed on six occasions from entry during their 17th year to age 25 to 27; results for 114 such men were analysed. The measurements were of stature, body mass, fat free mass and body fat, thoracic dimensions, forced expiratory volume and indices of forced expiratory flow, total lung capacity, and its subdivisions, transfer factor and Kco.

Results-At best about half the variance in the final lung function could be accounted for with the concurrent reference variables. For each lung function index the proportion of explained variance was substantially increased by also including in the prediction equation the pre-employment lung function expressed in standard deviation units.

Conclusion-Estimation of the longitudinal decline in lung function during adult life should be based on initial and final measurements of which the first should ideally be at age 25 but those at age 16 can be used instead: such measurements have long term value and should be preserved.
\end{abstract}

(British Fournal of Industrial Medicine 1993;50:422-427)

The assessment of impaired lung function of occupational origin is imprecise if only one set of observations is available. This is because the normal levels (reference values) have wide confidence lim-

Respiration and Exercise Laboratory, Department of Physiological Sciences, The Medical School, Newcastle upon Tyne NE2 4HH

D J Chinn, J E Cotes, M Fechner, C Elliott its so that a value in the lower part of the range may be normal or represent an enhanced decline from a previous above average level. These alternatives can usually be separated if results of lung function tests are available from before the exposure. The difference between the two sets of observations will then reflect the ages at the times of measurements, the occupational and medical history, the exposure to tobacco smoke, and the variability of the measurements. The age at first assessment should preferably be after that at which lung function has attained the adult value; the subsequent decline can then be compared with the longitudinal reference value. The critical age is greater for peak expiratory flow (PEF) and vital capacity (VC) than for forced expiratory volume in one second $\left(\mathrm{FEV}_{1}\right)$ and varies with circumstances; it is in the range 21 to 35 years, depending on the index, ${ }^{1}$ and the smoking history. ${ }^{2}$ Age 25 is usually taken as the average. ${ }^{3}$ For workers in many potentially dusty occupations, however, no measurements of lung function are made subsequent to this age except after the onset of symptoms, but measurements are sometimes made at the first pre-employment examination at age 16 to 17. Thus the present study asks the question: Can lung function at age 16 be used to improve the accuracy of the prediction of lung function in early adult life? A positive result would be a strong reason for assessing and recording lung function at the first pre-employment examination in persons who might subsequently be exposed to occupational air pollution.

\section{Subjects and procedures}

The subjects were young men entering shipyard apprentice training school during the year after their 16th birthday. The total intake in the year the study started was 277 of whom 271 were assessed. Five were subsequently excluded, two because they were not Caucasians and three because they were asthmatic. All the subjects were seen initially within four months of the start of training as part of their pre-employment examination before beginning work in the shipyard. Subsequently, they were invited to attend for reassessment at intervals of one to two years up to around age 21 , then for one 
further assessment between the ages of 25 and 29 . For the present study the initial, the final, and one set of intermediate results are reported. The procedures included the MRC questionnaire on respiratory symptoms (1976), detailed anthropometry, and measurements of lung function. The study was accepted by the local ethics committee.

\section{Methods}

\section{ANTHROPOMETRY}

Stature and sitting height were measured with a stadiometer and particular attention was paid to the adoption of a correct posture including traction to the head. For the sitting height the subject's feet did not touch the ground and the muscles of the buttocks were relaxed. Sternal notch height was also measured with the stadiometer but without head traction. Sternal length, midclavicular to subcostal length, shoulder and chest width, and depth at the end of a normal expiration were measured with an anthropometer. Skinfold thickness at four sites on the left side of the body (anterior and posterior midhumerus over the biceps and triceps muscles, below the angle of the scapula and above the anterior superior iliac spine) was measured with skinfold calipers. Body mass was measured on a beam balance calibrated with standard weights. The measurements conformed to the recommendations of the International Biology Programme. ${ }^{4}$ The sum of the four skinfold thicknesses was used to calculate the \% body fat by the method of Durnin and Womersley; 5 the fat free mass was obtained from this quantity and the body mass.

\section{LUNG FUNCTION}

Measures of $\mathrm{FEV}_{1}, \mathrm{FVC}$, and indices from the maximal expiratory flow volume curve were obtained with a dry bellows spirometer with digital output (McDermott). The spirometer was calibrated daily for volume and time with a syringe and standard weight and orifice. Three technically satisfactory expirations were recorded with the subjects in an upright seated posture and maximal values were used: the procedures were those recommended by a working party of the European Coal and Steel Community. ${ }^{6}$ Lung volumes were measured by the closed circuit helium dilution method with a resparameter ( $\mathrm{P}$ K Morgan), and transfer factor (TLCO) by the single breath carbon monoxide method with a resparameter in the initial surveys and transfer test equipment (P K Morgan) in the final survey. Breath holding time was calculated by the Jones and Meade convention, ${ }^{7}$ and transfer factor calculated with the lung volume measured from the dilution in the lung of the single breath of test gas. The linearity of the gas analysers was checked daily and standard procedures were adopted. ${ }^{38}$
STATISTICAL ANALYSIS

An Amdahl mainframe computer and the statistical package for the social sciences (SPSS ${ }^{x}$ ) were used. A 5\% level of probability was accepted as significant. The statistical procedures included multiple regression analysis in which the variables were entered in the order of their contribution to the variance explained by the regression. Colinearity between stature and other anthropometric indices was avoided by suitable transformations that included the use of body mass index (body mass/(stature $\left.{ }^{2}\right)$ ) instead of body mass. The other dimensional indices, including shoulder width and chest width, were standardised to the mean stature of the group by simple linear regression analysis. For purposes of analysis smoking was coded as yes or no at the time of each examination so no distinction was made between non- and ex-smokers.

\section{Results}

At initial assessment 24 subjects out of 266 reported one or more respiratory symptoms. Ninety five were current smokers and 49 were trainee welders or caulker burners. These 49 included significantly more smokers compared with the other tradesmen (59\% and $30 \%$ respectively). After allowance for stature the smokers had larger FVCs and hence smaller residual volumes as a percentage of total lung capacity (TLC) compared with the remainder (mean values for FVC 5.18 1 and 5.02 1 respectively). The differences were independent of respiratory symptoms. The smokers had a lower $\%$ fat and the difference in FVC was no longer significant when $\%$ fat was included in the analysis. The smokers also had lower mean values for TLCO and KCO (TLCO/alveolar volume): the values in SI units were 11.2 and 11.7 for TLCO and 1.97 and 2.11 for $\mathrm{KCO}$, for smokers and non-smokers respectively. These differences were independent of symptoms and of body dimensions and composition. Similarly, after allowing for stature the welders and caulker burners had larger residual volumes compared with the other tradesmen. They also had more respiratory symptoms but these did not contribute significantly to lung function.

The contributions of the several anthropometric and related indices to the description of the initial lung function was assessed by multiple regression analyses with indices standardised for stature; table 1 gives the equations derived for this purpose. After allowance for stature and smoking, the fat free mass $/$ stature, ${ }^{2}$ and to a lesser extent the body mass index, contributed more to the description of the indices of forced expiratory flow $\left(\mathrm{FEV}_{1}, \mathrm{PEF}\right.$, and maximum expiratory flow at $50 \%$ FVC $\left.\left(\mathrm{MEF}_{50 \% \mathrm{FvC}}\right)\right)$ and TLCo compared with the other anthropometric variables. The chest width contributed to the description of $\mathrm{VC}$ and related 
Table 1 Regression equations used to standardise the trunk dimensions for stature $(S t, m)$

\begin{tabular}{lcccc}
\hline & & & $S E E$ & $r^{2 *}$ \\
\hline Shoulder width (cm) & $21.8 \mathrm{St}$ & +0.2 & 1.95 & 0.41 \\
Chest width (cm) & $12.0 \mathrm{St}$ & +5.5 & 1.64 & 0.23 \\
Chest depth (cm) & $6.6 \mathrm{St}$ & +7.1 & 1.84 & 0.07 \\
Sternal length (cm) & $12.1 \mathrm{St}$ & -3.6 & 1.27 & 0.33 \\
Clavicocostal length (cm) & $18.0 \mathrm{St}$ & -1.9 & 1.52 & 0.44 \\
Trunk height (m)t & $0.28 \mathrm{St}$ & +0.1 & 0.026 & 0.39 \\
\hline
\end{tabular}

* Variance explained by the equation.

† Distance from stool to sternal notch with subject seated and buttocks relaxed.

indices. The other anthropometric indices made smaller contributions to the explained variance. Compared with stature, body mass index, and smoking the additional variance explained by fat free mass/stature ${ }^{2}, \%$ fat, and shoulder and chest widths was at most $6 \%$ in the case of FVC and less for the other variables. Thus only the more traditional indices were used to obtain reference equations describing the lung function of the apprentices at their first attendance. To avoid any possible effect from respiratory symptoms the analysis was confined to the results for the 242 subjects who were symptom free (table 2 ). The equations were then applied to the results for each subject individually with a view to describing their lung function in terms of standard deviation (SD) units about the mean values.

"Adult" lung function between the ages of 25 and 29 was obtained for 122 men. Eight of these men were receiving medication for asthma so the analysis was confined to the remaining 114 men. After allowance for stature the initial lung function of these men did not differ significantly from that of the remainder. With the exception of $\mathrm{FEV}_{1} \%$, $\mathrm{MEF}_{25 \% \mathrm{FvC}}$, and $\mathrm{KCO}$, the lung function on the second occasion was superior to that on the first occa- sion but the two sets of results were correlated (table 3). The subjects were also larger on the second occasion and the increases in bodily dimensions went some way to explaining the improvements in lung function. Thus for $\Delta \mathrm{FEV}_{1}, \Delta \mathrm{FVC}$, and $\triangle T L C$ the changes in the anthropometric indices accounted for about $50 \%$ (range $44 \%$ $54 \%$ ) of the changes in lung function. For $\Delta$ TLCO and change in functional residual capacity ( $\triangle \mathrm{FRC}$ ) the corresponding proportion of the variance which was explained was about $35 \%$. It was much less for the other indices. Intermediate results at age 21 were available for 84 of the men subsequently followed up. These results showed that by halfway through the study $\mathrm{FEV}_{1}$, FRC, and residual volume as \% of TLC (RV\%) had attained their adult levels but the other indices had not.

The final lung function measurements at ages 25-29 were analysed by multiple regression analysis with stature, body mass index, and smoking as independent variables. The proportion of the variance explained was similar to that at age 16 for FVC and TLC but less for the other variables. For each index the analysis was repeated including as an additional personal calibrating factor either the level of the relevant index (in SD units) at age 16 or the level for FVC (SD FVC). The inclusion of the factor for the index under investigation greatly increased the proportion of the variance explained by the regression. The SD FVC, however, although moderately useful in the case of $\mathrm{FEV}_{1}$, TLC, and $\mathrm{Kco}$, did not contribute much to the description of the other indices (table 4).

\section{Discussion}

Our present analysis is based on the results for 114 young men out of the 266 who met the initial criteria. The wastage is unlikely to have affected the result as the initial lung function of those who were

Table 2 Equations used to obtain lung function at age 16 in SD units ((obs-pred) $\div S E E)$

\begin{tabular}{|c|c|c|c|c|c|c|}
\hline & \multicolumn{3}{|c|}{ Regression coefficients } & \multirow[b]{2}{*}{ Constant } & \multirow[b]{2}{*}{$S E E$} & \multirow[b]{2}{*}{$r^{2 *}$} \\
\hline & $\begin{array}{l}\text { Stature } \\
(m)\end{array}$ & $\begin{array}{l}\text { Smoking } \\
\text { (if yes) }\end{array}$ & $\begin{array}{l}B M I \\
\left(\mathrm{~kg} \mathrm{~m}^{-2}\right)\end{array}$ & & & \\
\hline $\begin{array}{l}\text { FEV }_{1}(1) \\
\text { FVC (1) }\end{array}$ & $\begin{array}{l}5.44 \\
6.91\end{array}$ & ${ }_{-0.18}$ & $\begin{array}{l}0.043 \\
0.067\end{array}$ & $\begin{array}{l}-6 \cdot 16 \\
-8.39\end{array}$ & $\begin{array}{l}0.440 \\
0.491\end{array}$ & $\begin{array}{l}0.50(0.54) \\
0.57(0.63)\end{array}$ \\
\hline $\mathrm{FEV}_{1} \%$ (of FVC) & - & - & - & $83 \cdot 0$ & $6 \cdot 21$ & $-\quad-$ \\
\hline PEF $\left(1 s^{-1}\right)$ & 9.55 & - & 0.061 & $-9 \cdot 12$ & $1 \cdot 147$ & $0.30(0.32)$ \\
\hline $\mathrm{MEF}_{50^{\circ} \text {. FVC }}\left(\mathrm{ls}^{-1}\right)$ & $4 \cdot 76$ & - & 0.073 & -4.54 & 1.08 & $0.14(0.15)$ \\
\hline $\mathrm{MEF}_{25 \ldots, \ldots \mathrm{FC}}\left(1 \mathrm{~s}^{-1}\right)$ & $3 \cdot 14$ & - & - & $-2 \cdot 78$ & 0.72 & $0 \cdot 10(0 \cdot 10)$ \\
\hline TLCO (SI)† & 14.47 & -0.44 & 0.25 & $-18 \cdot 8$ & $1 \cdot 368$ & $0.52(0.56)$ \\
\hline KCO (TLCO/alveolar volume $) \dagger$ & $-0 \cdot 60$ & $-0 \cdot 14$ & 0.023 & $2 \cdot 67$ & $0 \cdot 213$ & $0 \cdot 17(0 \cdot 18)$ \\
\hline TLC (1) $\ddagger$ & $8 \cdot 73$ & - & 0.054 & $-10 \cdot 37$ & 0.608 & $0.56(0.65)$ \\
\hline RV (1) & $1 \cdot 88$ & & -0.016 & -1.922 & $0 \cdot 246$ & $0.25(0.29)$ \\
\hline RV \% (of TLC) & - & $-1 \cdot 17$ & -0.42 & $26 \cdot 1$ & 3.55 & $0 \cdot 10(0 \cdot 10)$ \\
\hline
\end{tabular}

* Variance explained by the equation. The maximal variance explained using the alternative or additional terms $\mathrm{FFM} / \mathrm{st}^{2}$, \% fat, shoulder width, chest width (see methods) is given in parentheses.

† Units mmol min ${ }^{-1} \mathrm{k} \mathrm{Pa}^{-1}$ and $\mathrm{1}^{-1}$.

$¥$ Calculated using inspiratory vital capacity and residual volume. 
Table 3 Mean results for 114 men seen on two occasions

\begin{tabular}{|c|c|c|c|c|c|}
\hline & \multirow[b]{2}{*}{ Initial } & \multirow[b]{2}{*}{ Final } & \multirow[b]{2}{*}{ Correlation } & \multicolumn{2}{|c|}{ Change* } \\
\hline & & & & Mean & $S D$ \\
\hline Age (y) & $\begin{array}{l}16 \cdot 8 \\
(16 \cdot 2-17 \cdot 6)\end{array}$ & $\begin{array}{l}26 \cdot 8 \\
(24 \cdot 7-29 \cdot 2)\end{array}$ & 0.23 & 10 & $1 \cdot 6$ \\
\hline Body mass $(\mathrm{kg})$ & $63 \cdot 6$ & $76 \cdot 9$ & 0.78 & $13 \cdot 3$ & $7 \cdot 5$ \\
\hline Stature $(\mathrm{St}, \mathrm{m})$ & 1.73 & 1.77 & 0.93 & 0.033 & 0.028 \\
\hline Shoulder width $(\mathrm{ShW}, \mathrm{cm}) \dagger$ & $38 \cdot 2$ & $40 \cdot 5$ & 0.71 & $2 \cdot 28$ & $1 \cdot 74$ \\
\hline Chest width $(\mathrm{ChW}, \mathrm{cm}) \dagger$ & $26 \cdot 4$ & $29 \cdot 1$ & 0.69 & $2 \cdot 74$ & 1.52 \\
\hline Chest depth $(\mathrm{ChD}, \mathrm{cm}) \dagger$ & $18 \cdot 4$ & $20 \cdot 6$ & 0.76 & $2 \cdot 18$ & 1.29 \\
\hline$\%$ Fat & $12 \cdot 4$ & $16 \cdot 1$ & 0.43 & $3 \cdot 68$ & $4 \cdot 44$ \\
\hline Body mass index (BMI, $\mathrm{kg} \mathrm{m}^{-2}$ ) & $21 \cdot 1$ & $24 \cdot 6$ & 0.68 & $3 \cdot 48$ & $2 \cdot 28$ \\
\hline Fat free mass (FFM, kg) & $55 \cdot 4$ & $64 \cdot 3$ & 0.82 & 8.9 & $4 \cdot 6$ \\
\hline $\mathrm{FFM} / \mathrm{St}^{2}\left(\mathrm{~kg} \mathrm{~m}^{-2}\right)$ & $18 \cdot 4$ & $20 \cdot 6$ & 0.72 & $2 \cdot 17$ & 1.33 \\
\hline Forced expiratory volume $\left(\mathrm{FEV}_{1}, 1\right)$ & $4 \cdot 22$ & $4 \cdot 37$ & 0.66 & $0 \cdot 15$ & 0.47 \\
\hline Forced vital capacity (FVC, l) & $5 \cdot 11$ & 5.63 & 0.75 & 0.52 & 0.53 \\
\hline $\mathrm{FEV}_{1} \%$ (of FVC) & $83 \cdot 0$ & $78 \cdot 0$ & 0.76 & $-5 \cdot 0$ & $4 \cdot 6$ \\
\hline Peak expiratory flow (PEF, $1 s^{-1}$ ) & $8 \cdot 67$ & $10 \cdot 54$ & 0.67 & $1 \cdot 87$ & $1 \cdot 12$ \\
\hline $\operatorname{MEF}_{50 \% \text { FVC }}\left(1 \mathrm{~s}^{-1}\right)$ & $5 \cdot 28$ & $5 \cdot 58$ & 0.71 & $0 \cdot 30$ & 1.06 \\
\hline $\mathrm{MEF}_{25 \%} \mathrm{Fvc}\left(\mathrm{ls}^{-1}\right)$ & 2.64 & $2 \cdot 16$ & 0.64 & -0.49 & 0.58 \\
\hline Transfer factor (TLCO, SI & $11 \cdot 6$ & $12 \cdot 3$ & 0.74 & 0.73 & 1.46 \\
\hline Kco (TLCo/alveolar volume $) \ddagger$ & $2 \cdot 07$ & $1 \cdot 87$ & 0.73 & $-0 \cdot 19$ & $0 \cdot 17$ \\
\hline Total lung capacity (TLCS, I) & 5.93 & $6 \cdot 88$ & 0.77 & 0.95 & 0.63 \\
\hline Residual volume $(\mathrm{RV}, \mathrm{l})$ & 1.00 & $1 \cdot 31$ & 0.62 & 0.31 & $0 \cdot 28$ \\
\hline RV\% (of TLC) & $16 \cdot 8$ & $18 \cdot 9$ & 0.57 & $2 \cdot 14$ & $3 \cdot 46$ \\
\hline
\end{tabular}

$\star p<0.05$.

+ For these indices the results are for 95 subjects.

$\neq$ Units $\mathrm{mmol} \mathrm{min}^{-1} \mathrm{kPa}^{-1}$ and $\mathrm{l}^{-1}$.

\& Calculated using inspiratory VC and RV.

seen was not different from that of those that lapsed. The serial measurements of lung function were made or supervised by the same person (DJC), with the same or similar equipment and rigorous calibration procedures throughout. The serial anthropometric measurements with the exception of the final ones were mostly made by one person; extrapolation of these results provided evidence that the final results were comparable with those obtained previously. Thus the present data were free from bias at follow up or technical error and the numbers were adequate for their purpose. The initial sample showed evidence for possible self selection of smokers who had a relatively large initial FVC but these features may have been a consequence of smoking as it was related to a relatively low \% fat, known to result from smoking. ${ }^{9}$ The smokers also had a low initial TLCO and above average declines in $\mathrm{FEV}_{1} \%$, FEFs at low lung volumes, and transfer indices; these features were consistent with previous work. ${ }^{1011}$ The finding that the trainee welders and caulker burners had an increased RV and included an increased proportion of smokers compared with other tradesmen is also consistent with previous experience. ${ }^{12}$ Only 17 of these men attended the final follow up, however, and by then most of them had been made redundant from the shipyard and were no longer working at their trade. Thus the effect of trade was unlikely to have contributed to the present findings, and they might therefore be expected to apply equally to young men in other heavy industries as well as to shipbuilding.
At the initial examination the absolute lung function was on average some $10 \%$ greater than that predicted from equations derived for children up to the age of $16 . .^{13}$ This finding is reasonable as the present subjects were somewhat older and might have been expected to be relatively robust. The present initial results were also representative in the proportion of variance that was explained by the regression equations. The proportion explained in the final results was somewhat less. The reasons for this seemed not to include differences in the time of attaining adult lung function as the proportion of explained variance in the final $\mathrm{FEV}_{1}$, which reached a plateau fairly early in adult life, was much less than that in the FVC, which reached a plateau later. Although final lung function had relatively wide confidence limits, the final levels were correlated with the initial levels and the changes between the surveys were correlated with the changes in stature or other reference variables. On this account the final levels could be described with greater accuracy in terms of initial lung function and the anthropometric variables together than by the anthropometric variables alone. The improvement was in all instances appreciable but especially so for those indices where the correlation with the dimensions was weak. This finding was consistent with expectations ${ }^{14}$ and recently a similar result was reported elsewhere. ${ }^{15}$ In the present study each index varied independently and no one index could be taken as representative; thus the use of FVC as a marker improved the estimation of FVC and those indices to which the FVC made an important con- 
Table 4 Regression equations describing final lung function (mean age 26.8) in terms of stature, smoking, and body mass index without and with additional terms for lung function (or FVC) measured at age 16

\begin{tabular}{|c|c|c|c|c|c|c|c|}
\hline & \multicolumn{4}{|c|}{ Regression coefficients } & \multirow[b]{2}{*}{ Constant } & \multirow[b]{2}{*}{$S E E$} & \multirow[b]{2}{*}{$r^{2 *}$} \\
\hline & $\begin{array}{l}\text { Stature } \\
(m)\end{array}$ & $\begin{array}{l}\text { Smoking } \\
\text { (if yes) }\end{array}$ & $\begin{array}{l}\text { BMI } \\
\left(\mathrm{kg} \mathrm{m}^{-2}\right)\end{array}$ & $\begin{array}{l}\text { Initial lung } \\
\text { function } \\
\text { (SD units) }\end{array}$ & & & \\
\hline \multirow[t]{2}{*}{$\mathrm{FEV}_{1}(\mathrm{l})$} & 3.90 & - & - & - & $-2 \cdot 52$ & 0.468 & $0 \cdot 25$ \\
\hline & 4.95 & - & - & 0.33 & $-4 \cdot 40$ & 0.351 & $0.58(0.35)$ \\
\hline \multirow{2}{*}{ FVC (1) } & $6 \cdot 88$ & - & - & - & -6.52 & 0.502 & 0.48 \\
\hline & & & - & 0.33 & -7.93 & 0.363 & $0.73(0.73)$ \\
\hline FEV \% (of FVC) & $\begin{array}{l}-28 \cdot 7 \\
-19 \cdot 8\end{array}$ & $\begin{array}{l}-2.89 \\
-1.90\end{array}$ & - & $\overline{-}$ & $129 \cdot 5$ & $6 \cdot 2$ & $0 \cdot 12$ \\
\hline \multirow{2}{*}{ PEF $\left(1 s^{-1}\right)$} & $6 \cdot 29$ & - & 二 & $4 \cdot 40$ & -0.57 & $\begin{array}{l}4.1 \\
1.30\end{array}$ & 0.10 \\
\hline & 7.64 & - & - & $0 \cdot 84$ & -2.94 & 0.99 & $0.48(0.13)$ \\
\hline \multirow{2}{*}{$\mathrm{MEF}_{50 \% \mathrm{Fvc}}\left(\mathrm{ls}^{-1}\right)$} & - & -0.70 & - & - & $5 \cdot 76$ & 1.48 & 0.04 \\
\hline & - & -0.44 & - & $1 \cdot 16$ & $5 \cdot 65$ & 0.98 & $0.58(0.04)$ \\
\hline \multirow{2}{*}{$\mathrm{MEF}_{25 \%} \mathrm{Fvc}\left(\mathrm{ls}^{-1}\right)$} & - & $-0 \cdot 38$ & -0.06 & - & 3.65 & $0 \cdot 66$ & 0.09 \\
\hline & - & -0.27 & -0.04 & 0.49 & 3.35 & 0.49 & $0.50(0.09)$ \\
\hline \multirow[t]{2}{*}{ Tlco (SI) } & 15.4 & -1.02 & - & - & $-14 \cdot 6$ & 1.55 & 0.38 \\
\hline & $15 \cdot 4$ & -0.86 & 0.11 & 0.89 & $-17 \cdot 4$ & 1.25 & $0.61(0.38)$ \\
\hline \multirow[t]{2}{*}{ Kco (SI) } & - & -0.13 & - & - & 1.91 & 0.23 & 0.06 \\
\hline & - & -0.15 & 0.022 & $0 \cdot 16$ & 1.38 & $0 \cdot 16$ & $0.75(0.16)$ \\
\hline \multirow[t]{2}{*}{ TLC } & $9 \cdot 45$ & - & - & - & $-9 \cdot 81$ & 0.66 & 0.49 \\
\hline & $10 \cdot 2$ & - & - & 0.47 & $-11 \cdot 16$ & 0.47 & $0.75(0.67)$ \\
\hline \multirow[t]{2}{*}{ RV } & $2 \cdot 27$ & - & - & - & $-2 \cdot 70$ & 0.32 & 0.20 \\
\hline & 2.43 & - & - & 0.19 & $-2 \cdot 98$ & $0 \cdot 27$ & $0.44(0.20)$ \\
\hline \multirow[t]{2}{*}{ RV \% (of TLC) } & - & - & - & - & $18 \cdot 9$ & $3 \cdot 8$ & \\
\hline & - & - & - & $2 \cdot 31$ & $19 \cdot 1$ & $3 \cdot 2$ & $0.31(-)$ \\
\hline
\end{tabular}

\#Variance explained by the regression. Term in parentheses is variance explained using (SD FVC) instead of the actual index (for example, SD FEV 1 ).

tribution but the prediction of the other indices was not much improved. This is consistent with the relation between reference variables generally. ${ }^{16}$

In healthy young men the ages above which the lung function reaches and remains on a plateau varies depending on the factors mentioned earlier. Subsequently, the lung function declines. The average age at the start of the decline for the shipyard population where the present subjects were apprentices, was similar to that reported for other groups. ${ }^{1718}$ The results suggest that for $\mathrm{FEV}_{1}$ and FVC the age of 27 , which was the age at final assessment in the present subjects, is an appropriate starting point for estimating the decline in lung function during adult life. If the lung function at this age is known the annual decline up to the subject's actual age can be obtained.

Interpretation of the rate of decline in lung function in an individual subject is inevitably approximate as the reference values have wide confidence limits. ${ }^{19}$ An impression can often be gained, however, as to whether the decline is normal or probably increased and this information can be of practical value in relation to smoking and occupational exposures. Thus for persons in occupations in which there may be a respiratory hazard the lung function should preferably be measured between ages 25 and 27 and recorded for subsequent use, but the procedures for doing this are only established in a few industries. Our results suggest that if the lung function at the plateau is not available, it can be estimated with appreciably greater accuracy from a regression equation that includes lung function at age 16 together with the subject's current stature, body mass, and smoking history, instead of an equation based on the reference variables alone.

Lung function at age 16 is often used as a screening test for respiratory disease as part of a pre-employment examination. We suggest that the values so obtained also have a long term significance nearly as great as those for age 25 . Thus results obtained at these or intermediate times during the period when the lung is maturing should be preserved for possible future use. Ways for doing this should be devised.

We are indebted to Dr J F Wollaston for access to the subjects, Dr J W Reed, and Dr Nicola Robinson for advice and help, the European Coal and Steel Community, Health and Safety Executive, Medical Research Council, and Wellcome Trust for financial support, and Mrs A B Blackhall for secretarial assistance.

1 Hurwitz S, Allen J, Liben A, Becklake MR. Lung function in young adults: evidence for differences in the chronological age at which various functions start to decline. Thorax 1980;35:615-9.

2 Tager IB, Segal MR, Speizer FE, Weiss ST. The natural history of forced expiratory volumes. Effect of cigarette smoking and respiratory symptoms. Am Rev Respir Dis 1988; 138:837-49. 
3 Cotes JE. Lung function: assessment and application in medicine, 4th ed. Oxford: Blackwell Scientific Publications, 1979.

4 Weiner JS, Lourie JA, eds. Practical Human Biology. London: Academic Press, 1981.

5 Durnin JVGA, Womersley J. Body fat assessed from total body density and its estimation from skinfold thickness: measurements on 481 men and women aged from 16 to 72 years. Br 7 Nutr 1974;32:77-97.

6 Quanjer PHH, ed. Standardized lung function testing. Bull Eur Physiopathol Respir 1983;19(suppl 5):1-95.

7 Jones RS, Meade F. A theoretical and experimental analysis of anomalies in the estimation of pulmonary diffusing capacity by the single breath method. Quarterly fournal of Experimental Physiology 1961;46:131-43.

8 Chinn DJ, Naruse Y, Cotes JE. Accuracy of gas analysis in lung function laboratories. Thorax 1986;41:133-7.

9 Karvonen M, Orma E, Keys A, Fidanza F, Brozek J. Cigarette smoking, serum-cholesterol, blood pressure and body fatness. Lancet 1959;1:492-4.

10 Tockman M, Menkes H, Cohen B, Permutt S, Benjamin J, Ball WC Jr, et al. A comparison of pulmonary function in male smokers and nonsmokers. Am Rev Respir Dis 1976; 114:711-22.

11 Knudson RJ, Kaltenborn WT, Burrows B. The effects of cigarette smoking and smoking cessation on the carbon monoxide diffusing capacity of the lung in asymptomatic subjects. Am Rev Respir Dis 1989;140:645-51.

12 Chinn DJ, Stevenson IC, Cotes JE. Longitudinal respiratory survey of shipyard workers: effects of trade and atopic status. $\mathrm{Br}$ F Ind Med 1990;47:83-90.

13 Cotes JE, Dabbs JM, Hall AM, Axford AT, Laurence KM Lung volumes, ventilatory capacity and transfer factor in healthy British boy and girl twins. Thorax 1973;28:709-15.

14 Oldham PD. Measurement in medicine. The interpretation of numerical data. London: English University Press, 1968.

15 Hopper JL, Hibbert ME, Macaskill GT, Phelan PD, Landau LI. Longitudinal analysis of lung function growth in healthy children and adolescents. F Appl Physiol 1991;70:770-7.

16 Williams RJ. Standard human beings versus standard values. Science 1957;126:453-4.

17 Lawther PJ, Brooks AGF, Waller RE. Respiratory function measurements in a cohort of medical students: a ten-year follow-up. Thorax 1978;33:773-8.

18 Burrows B, Lebowitz MD, Camilli AE, Knudson RJ Longitudinal changes in forced expiratory volume in one second in adults: methodologic considerations and findings in healthy nonsmokers. Am Rev Respir Dis 1986;133:974-80.

19 Berry G. Longitudinal observations, their usefulness and limitations with special reference to the forced expiratory volume. Bull Eur Physiopathol Respir 1974;10:643-55.

Accepted 27 July 1992

\section{Correspondence and editorials}

The British Journal of Industrial Medicine welcomes correspondence relating to any of the material appearing in the journal. Results from preliminary or small scale studies may also be published in the correspondence column if this seems appropriate. Letters should be not more than $\mathbf{5 0 0}$ words in length and contain a minimum of references. Table and figures should be kept to an absolute minimum. Letters are accepted on the understanding that they may be subject to editorial revision and shortening.

The journal now also publishes editorials which are normally specially commissioned. The Editor welcomes suggestions regarding suitable topics; those wishing to submit an editorial, however, should do so only after discussion with the Editor. 